\title{
As encenações da História
}

Sheila SCHVARZM AN ${ }^{1}$

RESUMO: A H istória foi um tema muito presente nos filmes brasileiros da década de 1990. Buscava-se, por seu intermédio, dar aos filmes prestígio e credibilidade, atraindo investidores para o seu financiamento, conforme as novas leis de incentivo à cultura. $\mathrm{A} H$ istória tornou-se alvo de interesse renovado com a proximidade das comemorações dos quinhentos anos do "descobrimento" do Brasil, e o cinema se encarregou de produzir filmes sobre momentos e personagens consagrados. Esse artigo procura analisar como a História foi encenada nesses filmes e o seu resultado.

Palavra S-Chave: História do Brasil, anos 90, cinema eHistória.

A História éum tema recorrente do cinema desde os seus primórdios, entretanto os sentidos de sua utilização sempre foram diversos. Se no início do cinema se transpunham dramas literários ou teatrais de época, ${ }^{2}$ que transferiam para o cinema o prestígio de uma forma artística consagrada, autenticando os poderes de representar a alta cultura de que o divertimento popular ainda se ressentia, era sempre com pretensões grandiosas, ou marcando algum progresso na linguagem ou equipamento cinematográfico que a história aparecia como tema. A H istória sancionava, por sua seriedade, pela idéia de verdade a ela associada, a importância do cinema, um divertimento popular.

Se isso cabe para explicar em parte o sucesso de 0 nascimento de uma nação, de 1914, que alça o cinema em definitivo à categoria de um divertimento burguês, pois a narrativa fílmica, tal qual a conhecemos hoje nele se articula e se consagra, cabe lembrar também que 0 descobrimento do Brasil, de Humberto Mauro, realizado em 1937, foi a primeira superprodução brasileira: foram gastos 500 contos de réis, com a ajuda de especialistas como Roquette Pinto, Affonso de Taunay, e Hei- 
tor Villa Lobos: "Já podemos realizar verdadeiros filmes históricos", observava o jornal A N oite, ${ }^{3}$ exaltando a grandiosidade do empreendimento, que selaria o início da verdadeira e agora definitiva cinematografia nacional. ${ }^{4}$

Nos anos 1950, quando a Companhia Cinematográfica Vera Cruz ${ }^{5}$ procurava afirmar-se como lugar de maior competência na real ização de filmes brasileiros, empregando padrões internacionais de produção e vários técnicos estrangeiros, o diretor Lima Barreto produziu 0 Cangaceiro. Esta obra consagrou o filme de cangaço como um gênero cinematográfico, misturando aventura, sertão, $\mathrm{H}$ istória nacional e seus mitos populares. Criava-se o nordestern, ${ }^{6}$ gênero fértil nos anos 1960 e que, com mudanças, persiste até hoje. ${ }^{7}$

Durante a ditadura militar, período em que a produção de filmes brasileiros éfortalecida pelo apoio estatal, é significativo o número de obras de cunho histórico, mas é sobretudo como espaço metafórico que o passado éinvocado, servindo de alegoria por meio da qual se pode falar do arbítrio dos tempos presentes, como na encenação dos Autos da Devassa em Os inconfidentes, de J oaquim Pedro de Andrade, em $1972^{\circ}$. Independência ou morte, ao contrário, produção de Oswaldo $M$ assaini, celebra a autoridade do imperador que governa através de uma constituição manietada pelo A to Adicional, elouva-se a autoridade que contém a desordem.

No Brasil de meados dos anos 1990, a H istória seria mais uma vez convocada. Servira, em especial, de caução para justificar e afirmar a existência de um cinema brasileiro cuja pertinência foi mais uma vez não apenas questionada, mas até mesmo negada, já que no início do governo de Fernando Collor (1989-1992) se extinguiram os dois organismos - a Embrafilmee o Concine - até então responsáveis por políticas de auxílio à produção e à exibição de filmes nacionais. Com a criação das leis de incentivo (Lei Rouanet, Lei do Audiovisual) para a produção cinematográfica, por meio da dedução de impostos de empresas, o financiamento e a própria existência do cinema brasileiro ficam atrelados à imagem mercadológica que a obra poderá agregar à empresa que o financia. É dentro dessa lógica política e econômica que a História será chamada a desempenhar, no cinema brasileiro, um pa- 
pel logístico: deve ajudá-lo a encontrar novos mecenas e um público perdido. $^{9}$

Diante de tantas e tais expectativas, procuraremos analisar, em algumas obras significativas, de que forma o filme de tema histórico dos anos 1990 serviu, imaginariamente, para dar credibilidade ao cinema brasileiro. De que forma essa operação foi construída, e, para tanto, que momentos e personagens recuperou e, sobretudo, qual o resultado dessa operação.

Carlota Joaquina, filme de tema histórico, foi um grande sucesso de público em 1994. Esse ano e esse filme tornaram-se marcos do que se convencionou chamar de "retomada do cinema brasileiro".

\section{UM OUTRO OLHAR}

Carlota Joaquina foi um filme marcante não apenas pelo seu êxito. No início da década, com o cinema brasileiro desmantelado, foi capaz de propor uma nova encenação da História do Brasil, e restou como paradigma de filme que dialogou com um novo público para o cinema nacional, e como tal trabal hou para criá-lo. 0 filme, realizado com recursos bastante escassos, teve de se coadunar às novas exigências de financiamento baseado no apoio da iniciativa privada, e soube tirar partido dessas restrições com inventividade.

Com Carlota Joaquina, de 1994, Carla Camurati propôs uma nova leitura da H istória do Brasil no cinema. Seu filme trata da vinda da Família Real, momento em que o Brasil começava a se liberar do jugo colonial e se abria ao mundo, ainda que servindo exclusivamente aos interesses de Portugal.

Para poder olhar essa história de um novo ângulo, a diretora se serve de Carlota Joaquina, personagem de pouquíssima expressão na historiografia nacional. É a partir dos seus olhos, duplicados pelo olhar contemporâneo de uma menina escocesa - duas mulheres estrangeiras que Camurati conduz a sua ação. Ao privilegiar o olhar de Carlota, a diretora recupera uma personagem que $\mathrm{H}$ istória deixou de lado, e pontua nessa operação o caráter transitório e politicamente determinado da 
escrita histórica. Lembra-nos quea H istória, como o cinema, corta, monta, obscurece ou ilumina um personagem ou diferentes fatos históricos conforme a leitura que o presente impõe ao passado.

Ao tornar Carlota Joaquina protagonista dessa história, a diretora faz com que portugueses e brasileiros sejam observados a partir dos seus olhos críticos, olhos de quem, como espanhola, se considerava superior, parte de uma cultura mais desenvolvida, culta e cheia de vivacidade, enquanto os portugueses são caracterizados como o pólo oposto: atrasados, incultos e covardes. A caracterização da corte espanhola se faz com a vivacidade do vermelho onipresente, que serve para marcar a sensualidade e a ação resoluta que caracterizaria os espanhóis. Já os portugueses, enfadonhos, vestem-se de preto, comem comida insossa e são carolas (como se os espanhóis também não o fossem). 0 branco, o preto e a onipresença de cruzes marcam, em contraposição, a cena portuguesa.

Desde o princípio, o filme mostra a iniciativa de Carlota, sua sensualidade e revolta contra a covardia, a indecisão e até a melancolia de D. J oão VI . Essa caracterização, certamente, faz a balança pender para Carlota como um pólo positivo, em oposição a um D. João medroso, dessexualizado, ainda que, à medida que o filme se desenvolve, vemos como o ímpeto ativo de Carlota se vêsistematicamente frustrado pelas maquinações silenciosas e espertas de D. J oão VI.

Entretanto, além de Carlota, há ainda outros narradores nessa história- o rapaz e a menina escocesa - que, do outro lado do continente europeu, falam da H istória do Brasil em inglês, como a pontuar o domínio dessa história a partir do exterior, pelos anglo-saxões, demarcando a dupla condição de dominados dos brasileiros.

A Corte Portuguesa, na visão do filme, foge vergonhosamente de Lisboa e aporta no Brasil, onde começa a modificar a vida da colônia, corrompendo os seus hábitos, promovendo políticas arbitrárias, desalojando seus habitantes.

Esse ponto de vista opõe-se ao da historiografia consagrada sobre o período, que viu na mudança da Corte para o Brasil uma aproximação com o O cidente - de que decorreriam a ruptura do isolamento secular da Colônia, o surgimento de novas instituições e o aguçamen- 
to das contradições que vão levar, enfim, à Independência. Já o filme empenha-se em investigar o contato desses europeus com o mundo tropical, imaginado inicialmente como um lugar rebaixado, de gente primitiva, como seriam negros eíndios, e de répteis ameaçadores que D. Maria I repele apavorada.

Entretanto, ao contrário das piores previsões, a gente da terra é afável: espera pela Família Real em desfile etnográfico. Índios e negros estão caracterizados conforme suas etnias, pintados como nos desenhos de Rugendas e D ebret. Carla Camurati se reapropria desses signos que os viajantes estrangeiros criaram e nos acostumaram a identificar como nossose os devolve a seu lugar de origem, organizados numa recepção em alas, num desfile de escola de samba, acompanhado do devido batuque. 0 trópico se assume como trópico, e incorpora as cores e a imagem que dele se criou. É como se duzentos anos depois desses viajantes, o Brasil realmente incorporasse o ol har estrangeiro como o seu próprio. Devolve-se ao olhar dos estrangeiros (Carlota Joaquina e a menina escocesa) as imagens que os haviam inspirado.

Camurati está interessada aqui em compreender por outros olhos e de outro ângulo uma história que consagra a elevação do Brasil a corte, sua aproximação com a Europa ali representada - o que era a Europa? - , contrastando este dado com a aparência que nos era dada a ver pelos viajantes que então aqui chegavam e nos construíam imageticamente.

Sua apropriação dos signos, reconvertidos novamente em signos de brasilidade, exótico, tropicalidade, é particularmente feliz no momento em que Carlota encontra o mulato dom Fernando, aderindo ela também, finalmente, à miscigenação, ao som grandiloquente do Ticotico no fubá de Zequinha de Abreu.

Num movimento semelhante, a diretora trabalha com outros signos típicos, que no filme renovam seu sentido. É o caso da música e da dança espanhola que caracterizam Carlota e seus familiares, que cantam e dançam sensualmente, duplicando no signo banalizado da eterna dançarina de castanhola na mão tudo o que resumiria popularmente, no Brasil, a essência dos espanhóis.

No Rio de Janeiro, a cortesia da população que recebe a corte se 
desdobra em subserviência, favor e trânsito de influência. A imitação do pano na cabeça das mulheres que vinham da Corte pela personagem da gorda brasileira, como última moda da Europa, quando o mesmo servia para esconder piolhos quetraziam da viagem, éum dos muitos focos da apropriação acrítica queo contato ea emulação despertam, e sobre o qual a diretora coloca um acento irônico. É como se a diretora quisesse caracterizar ali o momento inaugural de nossos mais abomináveis defeitos.

A vida na corte é contada de forma chanchadesca, não economizando no escracho e no escatológico. Com isso, a diretora recupera formas tradicionais de encenação que remetem aos filmes da Atlântida, a M acunaíma - o livro de $M$ ário de Andrade e o filme de Joaquim Pedro de Andrade - , e desconstrói a visão empolada da história que se pode ver em Independência ou morte, de 1972, e, mais recentemente, em Guerra de Canudos, de 1997, ou M auá, o imperador e o rei, de 1999, ambos de Sérgio Resende.

Ao mesmo tempo, ridicularizar a Família Real faz parte de uma Ionga tradição que o filme atualiza, ${ }^{10}$ reeditando D. João VI como 0 grande desengonçado, glutão comedor de frangos, imagem recorrente, usada durante quase todo o tempo (e devidamente tropicalizada pela introdução de gordas fatias de abacaxi), embora, como o próprio filme vai mostrar, ele é também capaz de inúmeras e bem-sucedidas maquinações políticas: manteve Portugal e o Brasil sob o seu controle (como já havia observado Oliveira Vianna) - ainda que muito ajudado pelos ingleses - e frustrou todas as tentativas de autonomia (pessoal ou política) de Carlota Joaquina.

Carla Camurati usa também do esquema da TV Pirata, programa cômico da TV Globo que fazia muito sucesso naquele momento eque, da mesma forma que o filme, abusava do registro chanchadesco, criticando o cinismo do período. Ao longo do filme, vai se instalando um mal-estar que local iza, naquela história, as mazelas de que éramos acometidos no início dos anos 1990. Em seu artigo sobre o filme, Jean Claude Bernardet ${ }^{11}$ critica esse viés que, ao depositar nos portugueses os defeitos nacionais, dissolve toda a ação dos brasileiros, e com eles, toda a sua história. 
Diante desse acerto de contas com a colonização portuguesa que a diretora vê como um fenômeno unicamente predatório, somos levados a nos perguntar, afinal, a quem exatamente se dirigiam essas críticas em 1994?

Carlota Joaquina foi realizado num momento em que o cinema brasileiro praticamente tinha deixado de existir, destruído pelas medidas neoliberais de Fernando Collor de M ello. Collor tinha um apego particular pela extinção do cinema brasileiro, que procurou efetivar de maneira truculenta. Criticava seu financiamento pelo Estado, por meio da Embrafilme, e acreditava que, como outras atividades, devia ser regido pelo mercado e financiado pela iniciativa privada.

Instituições que haviam garantido a existência do cinema brasileiro em mais de vinte anos foram extintas. 0 número de filmes produzidos e exibidos reduziu-se a quase zero entre 1990 e 1994. 0 cinema brasileiro foi condenado ao desaparecimento como desnecessário, dispendioso e, sobretudo, duvidoso.

Em meio a esse descrédito, Carlota Joaquina foi lançado em 1995. A boa aceitação do filme pelo público, a freqüência de 300 mil espectadores, inédita naquele momento para um filme nacional, marcou 0 que acabou se configurando como a "retomada do cinema nacional". E marcou não só porque a diretora fez seu filme com poucos recursos e com o auxílio de patrocínio, mas porque conseguiu dialogar com o público.

Se esse sucesso pode ser atribuído à encenação criativa, que dispensa grandes cenários reconstituídos e inventa sua própria estética para o século XIX, recuperando os signos exóticos e típicos criados sobre o trópico, por outro lado a mudança do foco sobre a H istória ea crítica sem complacência às raízes ibéricas parecem ter feito eco junto ao público, principalmente de classe média, que voltava agora a observar o que se faz no cinema brasileiro.

Depois de viver um período de muita corrupção e no reino das falsas aparências que foi o governo Collor, em que se deu uma nova e ilusória Abertura dos Portos, o público parece partilhar com a diretora de uma crise de auto-estima que é preciso exorcizar, Encontrar essas raízes na caracterização ridícula e predatória das origens faz rir, mas é 
ainda uma forma vitimizada de ver as coisas, que exclui dos brasileiros, no passado como no presente, seu papel de sujeitos de sua própria história.

Não é um procedimento novo nem original, é uma tradição bem brasileira, aliás. 0 complexo de vira-lata a que se referia $\mathrm{N}$ elson Rodrigues ou as perorações deVieira ou Gregório de Mattos contra a colonização portuguesa predatória não eximem, no entanto, os brasileiros de suas próprias ações, como parece sugerir o filme.

Essas limitações enfraquecem e dissolvem parte significativa da crítica que se constrói ao longo do filme, fato apontado também por Jean-Claude Bernardet na época do lançamento, lembrando ao mesmo tempo a boa acolhida do público a essa visão:

O que pensar de uma sociedade ou de um segmento de sociedade que aplaude espetáculos de que a história, o drama, o conflito foram eliminados, empurrados para fora do espetáculo? De que maneira essa socie dade vive e faz a sua história? Devo dizer que Carlota Joaquina (...) parecedar umaresposta bastantenegativa aessa questão, como sea construção dramática desses espetáculos refletisse uma falta, uma carência de iniciativa histórica. ${ }^{12}$

Entretanto, esse movimento de al heamento da responsabilidade histórica, que o filme constrói, é bem característico da dissolução da idéia de H istória, própria dos anos 90 . 0 filme torna-se, voluntariamente ou não, sua testemunha.

USOSE ABUSOS DA HISTÓRIA

Se a chanchada de Carla Camurati firmou a retomada do cinema brasileiro, a década foi ainda muito marcada pelo viés histórico que pode ser atribuído seja às comemorações dos quinhentos anos do "descobrimento", que criaram a demanda em torno de temas como Hans Staden (1999) ou Caramuru (2000), seja pela dependência do patrocínio financeiro de grandes empresas, em que a seriedade da reconsti- 
tuição histórica parece inspirar mais seriedade e empenho do que trabalhos propriamente ficcionais. A volta aos ambientes burgueses e imperiais do século XIX foi um dos momentos preferidos, com Amor e cia (1998), ou Mauá, o imperador e o rei (1999) - elogio da livre iniciativa figurada em M auá, soterrado em seus empreendimentos pela incompreensão de D. Pedro II, ou melhor, do Estado. Sérgio Rezende, o diretor, pinta o retrato de um grande empreendedor frustrado e de uma al ma conciliadora: M auá bebe cachaça e acompanha a morte de um ex-escravo. Iniciativa privada e conciliação social dão o tom, num dos filmes mais falsos, certamente oportunista e mais mal dirigidos desta temporada.

Os desvãos do nacional ismo ficam por conta de um apenas ilustrativo Policarpo Q uaresma (1998), de Paulo Thiago, e a literatura de M achado de Assis garante não só o naco de financiamento e público, mas também o mercado escolar para um correto M emórias póstumas de Brás Cubas (2000). H ouve ainda uma nova encenação de 0 Guarani (1996), por Norma Benguel, incursão infeliz pelo início da colonização que resta ainda, para o cinema, como um período de difícil montagem. Para escapar à aridez desses tempos - pelo menos é assim que o cinema os apresenta - os diretores recorrem às idealizações românticas de J osé de Alencar e à matriz dos mitológi cos bandeirantes, que aparecem desta vez num filme de aventuras para adolescentes, No coração dos deuses (1999), de Geraldo M oraes, onde a busca de um tesouro, a partir de um mapa do século XVII, faz os personagens viajarem da atualidade ao passado, quando enfrentam índios e invasores. Aqui, ao oportunismo histórico soma-se o oportunismo didático.

Tiradentes não foi esquecido. Chegou também em 1999, próximo à comemoração dos quinhentos anos, ano de maior lançamento de títulos históricos, ${ }^{13}$ mas veio renovado. De mártir maior da Inconfidência, ${ }^{14}$ transformou-se em símbolo sexual. A antiga imagem pictórica de Pedro Bruno, que o associava a Jesus, ou a imagem de um subversivo em O s inconfidentes (1972), de Joaquim Pedro de Andrade, perdem espaço para um musculoso ator denovelas. Nasmãosde O swaldo Caldeira, a trama histórica concorre com romance e sensualidade.

Em cada um desses filmes recentes, a relativa abundância de re- 
cursos financeiros e a falta de uma concepção histórica própria levam diretores a apenas repetir visões consagradas pela literatura ou historiografia, e a necessidade de bom acabamento leva à criação de reconstituições cuidadas do ponto de vista do cenário, do guarda-roupa, da linguagem e dicção, como se isso esgotasse em si a própria idéia do passado. Os filmes se enchem agora de novos profissionais responsáveis pelos infinitos detalhes da direção de arte, como se a H istória se desvendasse a partir da sua aparência. Esse é certamente o viés que orienta a encenação do que seria um dos maiores temas nacionais, a Guerra de Canudos (1997), de Sérgio Rezende, produção custosa, na qual a visibilidade e a ilustração da história resumem seu conteúdo.

Essas produções são marcadas por um extremo academicismo em sua encenação. São narrativas respeitosas com a cronologia e a encenação linear dos fatos, dotados de um olhar cerimonioso em relação aos personagens e acontecimentos. É como se os filmes instalassem uma visão oficial e solene da história que, nesse caso, a historiografia já procurou abandonar. Em geral ilustrativos, não sugerem mais do que esforços pál idos diante dos originais em que se baseavam. Quando nos lembramos de D eus e o diabo na terra do sol (1964) e sua interpretação de Os Sertões, é com pesar que se observa quanto a compreensão de um processo histórico passa nos anos 90 a se resumir apenas à encenação da sua aparência, como se vê em Guerra de Canudos. N ão é do interior dos fenômenos que vêm a análise e o sentido desses filmes, mas da pura formalização, como se levar histórias para a tela fosse já operação suficiente e definitiva, como a testemunhar justamente o vazio de idéias que se substitui pela onipresença da estética e da técnica, sobre o que, aliás, o público nacional agora não tem mais reclamações ${ }^{15}$. A grandiosidade e o apuro das reconstituições são a afirmação de que o cinema brasileiro ultrapassou, enfim, suas limitações.

É dentro desse mesmo raciocínio que se pode introduzir VillaLobos (2000), de Zelito Vianna. Ilustrativo e protocolar, apesar de certo empenho em mostrar os ímpetos nacionalistas do compositor com seus gigantescos corais durante a ditadura Vargas - que a imagem não é capaz de reproduzir devida ou inventivamente o que prejudica o fil- 
me - o que se sobressai éa vida íntima, os amores de Villa-Lobos e um certo tom nostál gico com relação ao passado vivido pelo maestro.

Fugindo aos personagens históricos consagrados e dedicando-se a Lamarca (1994), guerrilheiro de esquerda, o tom solene e circunspecto que Sergio Rezende empregaria em Guerra de Canudos e M auá, 0 imperador e o rei, já está presente. Se a biografia do capitão tenta dar alguma densidade dramática ao personagem, a cena da sua morte, deitado sendo baleado sem defesa e restando morto com os braços abertos como um Cristo, sugerem um fim covarde ou um sacrifício em nome da pátria.

É óbvia a regressão nas concepções históricas e fílmicas recentes. A História é um acontecimento separado do presente, sem reflexos ou repercussão, ainda que muitos dos cineastas apregoem suas pretensões de compreensão sobre o Brasil a partir do cinema. Quanto à encenação, não é capaz de se descolar do mimetismo criando um jeito próprio de contar a história, como fizeram Carla Camurati, Glauber Rocha ou Joaquim Pedro deAndrade.

Desse ponto de vista, só se pode concluir que a abundância de recursos e a parceria com a iniciativa privada contribuíram para tirar do cinema brasileiro toda a veleidade criativa, a liberdade crítica, a reflexão histórica conseqüente. Esses filmes compõem no cinema uma visão museológica da história. São peças da vitrine de um sistema que entrega a gerentes de marketing a definição comportada e conformada da produção artística de um país, e no qual a H istória perde qualquer significação ativa para tornar-se apenas o espetáculo do já devidamente morto e dominado, acessível a professores e alunos para suas visualizações do passado.

A H istória, mestra da vida, conforme se pode ver por grande parte desses filmes, é um depósito de personagens e acontecimentos consagrados e de compreensão devidamente instalada, de que se pode dispor sem problemas. 0 presente os atualiza pela cerimônia da própria reconstitui ção, que reinscreve os temas numa nova oficialidade, a do monumento fílmico. Servem de ilustração ao já conhecido, atualizado pela visão apenas expositiva do assunto, garantida pelo bom uso da técnica. N ão mudaram os personagens enfocados, e sobretudo o ângulo 
sobre o qual a história é observada (salvo exceções, como Carlota Joaquina). $\mathrm{O}$ cinema instala uma compreensão cosmética da $\mathrm{H}$ istória, a partir das camadas dominantes e para as camadas dominantes.

O QUE É ISSO, COMPANHEIRO?

0 que é isso, companheiro(1997), de Bruno Barreto, foi realizado para comemorar os 30 anos dos acontecimentos de 1968 no Brasil, quando o regime militar e grupos terroristas se enfrentaram. 0 que dá tom ao filme, no entanto, é antes a lógica harmonizadora do presente. 0 que promove não éa memória, e sim o esquecimento.

Em meados dos anos 70, Michel Foucault ${ }^{16}$ apontou os mecanismos da perda de memória espontânea que, desde meados do século XIX, vinha sendo substituída por uma memória correta, harmonizada em seus contrastes, produzida pelos meios de comunicação de massa. 0 que éisso, companheiro (1997) é um excelente exemplo desse tipo de procedimento.

Em nome do resgate de um momento histórico, a memória espontânea foi atualizada e constrangida pelas necessidades do presente. O filme é uma adaptação do livro de Fernando Gabeira, que conta a história do sequestro do embaixador americano em 1968 e o destino dos militantes empenhados nessa ação. No livro, 0 autor narrou 0 engajamento diante da situação de arbítrio em que se vivia na época ea tentativa de se opor a ela. De que forma o filme retraçou essa história?

0 espectador é introduzido na trama de um filme de aventura. Ele vêum assal to a banco e depois acompanha um seqüestro. Os personagens falam de suas esperanças, mas como não há um contexto para a ação desses jovens, sua ação permanece isolada, portanto sem sentido, fruto do voluntarismo de um bando de imaturos radicais.

Isso se torna mais pal pável na construção da narrativa pelo contraponto criado entre o grupo de seqüestradores (há entre eles um sanguinário cruel), e a figura do torturador, representado como homem ponderado, educado e cumpridor do seu dever. Existe, assim, uma clara inversão de papéis. A crueldade que se pode atribuir a um tortura- 
dor é exercida pelo personagem do guerrilheiro Jonas. Isto não está no livro, é uma formulação original do filme, que instaura assim um novo entendimento, conciliador, ditado pelo presente.

Se os jovens são apresentados como despreparados, levados por ideais e paixões, incapazes de medir as conseqüências de seus atos, 0 torturador do filmeé, ao contrário, consciente. 0 olhar humanizado que o filme lança sobre ele traveste o personagem e neutraliza os demais personagens, privando seus atos de outro sentido que não a própria imaturidade, isto é, privando-os de qualquer significado político. 0 torturador reveste-se das roupagens de um ponderado burocrata, explicando à sua bela esposa-na cama, de baby doll - que faz aquel e trabalho porque recebe ordens superiores, eque tortura, sim, mas que são crianças, meninos desencaminhados. Bruno Barreto cria aí a imagem de um torturador funcionário público (imagem curiosa, pois para 0 pensamento neoliberal em pleno vigor na época o funcionário público não seria uma espécie de torturador que atravanca o bom andamento dos negócios de Estado? Esse torturador zeloso de suas obrigações não deixa de ser a imagem refletida desse funcionário).

É a observação paternal desse torturador sobre suas vítimas, a preocupação com as restrições da esposa à tortura, lembrada enquanto faz a escuta do grupo clandestino, que ordena o filme, indicando um olhar de complacência em relação aos jovens. Um olhar moderado, que contrasta com a radicalidade dos jovens.

Desta forma, as desventuras dos jovens de ontem aparecem como justificativa do conformismo de hoje. A juventude do fim dos anos 60 e sua crença na ação política é que são seqüestradas pelo filme e enquadradas numa crença atual, segundo a qual o jovem, conformado pelo consumo, deve ser incapaz de agir sobre a realidade, como haviam feito outros no passado.

Desta forma, as desventuras dos jovens de ontem aparecem como justificativas do conformismo de hoje. 0 torturador éo elemento consciente, dir-se-ia, quase moderado, enquanto os jovens se perdem por incompetência e idealismo. 
O cinema buscou na história prestígio e segurança. Realizaramse obras em sua maioria de resultado acadêmico, cuja repercussão junto ao público raramente correspondeu às expectativas do alto investimento que exigiram. $\mathrm{O}$ carisma da H istória não foi suficiente, na maior parte das vezes, para atrair um número significativo de espectadores, nem tampouco para encobrir a ausência de idéias fílmicas ou históricas. Carlota Joaquina, nesse sentido, é o exemplo contrário: fugiu do mimetismo da reconstituição, criou seu próprio ponto de vista sobre o tema, e o fez com poucos recursos. Parecia inaugurar um caminho que não se desenvolveu, na medida em que outros filmes não agregaram nem ao cinema e nem à história novos pontos de vista sobre os temas tratados.

Restam os filmes como testemunho da submissão a interpretações históricas consagradas e da forma mercadológica de ver e consumir a história, vigente no Brasil no período da comemoração dos quinhentos anos do "descobrimento". Restam também para ilustrar o ensino da H istória nas escolas, reproduzindo suas visões celebratórias, solenes e conciliadoras.

\section{"A PEQUENA HISTÓRIA"}

Contrariando esse ponto devista, filmes que não tomam a reconstituição como o seu objetivo central, que não julgam fazer a tarefa hercúlea de transpor os mistérios do passado para a compreensão de todos, mas apenas contar uma boa história, terminam por ser mais bem sucedidos. Como têm um ponto de vista próprio sobre aquilo que narram, constroem o que M arc Ferro denomina de "reconstruções históricas", visões autônomas e iluminadoras sobre aquilo que mostram. ${ }^{17}$

Filmes que abordam a $\mathrm{H}$ istória não se resumem à grande $\mathrm{H}$ istória. Outros sem pretensões grandiosas foram mais bem-sucedidos. É o caso de Dois córregos (1993), de Carlos Reichenbach, e Baile perfumado (1996), de Paulo Caldas e Lírio Ferreira. D ois córregos poder ser visto em contraste com 0 que é isso, companheiro, pois também trata de um guerrilheiro. Uma mulher, de volta a uma antiga propriedade da 
família, recorda o seu passado e selembra de um tio queali estava, clandestino, nos anos 70. Entre as suas lembranças e as do tio somos inseridos na atividade de um guerrilheiro, suas lembranças e dores, e por fim no seu desaparecimento.

Reichenbach contava uma reminiscência pessoal, na qual o cotidiano de moças em férias é entrecruzado pelos acontecimentos históricos e opções políticas. A H istória ali deixa de estar exilada no passado, perde a solenidade e se integra ao vivido. A guerrilha é observada como a escolha do personagem. M ais do que julgar, o filme conta essa história através da memória pessoal, que étambém a memória do País.

Baile perfumado narra a história de Benjamin Abrahão, imigrante árabe que filmou Lampião e seu bando nos anos 30. Por meio desse personagem, o filme resgata a atividade dos "cavadores", comum no cinema brasileiro entre os anos 1910 e 1930. Esses "mascates de vista", como eram chamados, eram em grande parte estrangeiros e faziam filmes por encomenda sobre as cidades, filmes de propaganda, filmes de família, ou propunham temas de interesse, como apresentar a imagem de Lampião e seu bando, assunto que suscitava grande curiosidade popular. Através de Abrahão e do cinema, o filme percorre o Nordeste, 0 cangaço, suas redes de poder, estabelecendo um novo ponto de observação. Entre os cangaceiros, A brahão acompanha a vida do bando e a realização do documentário: a curiosidade pelo cinema, a vontade de se verem retratados.

Baile perfumado mostra o documentário realizado em 1935, partilhando com o espectador as parcas imagens originais que restaram em arquivo fílmico. Elas são a sua inspiração e o documento do qual se tira a cuidadosa reconstituição dos gestos dos cangaceiros.

A questão central do filme é a constituição da imagem cinematográfica de Lampião e a atração e os perigos de sua divulgação. É por meio dela que o filme vai observar a relação dos coronéis nordestinos com o cangaço, o controle de Lampião na construção de sua imagem - já que é el e quem dita ao cineasta como deve ser filmado - e, por fim, terminada a filmagem, a interdição de exibi-lo. Lampião se tornara muito popular e não convinha ao governo de Getúlio Vargas, que o perseguia, permitir a sua exposição simpática nos cinemas. Por conta 
disto, Benjamin Abrahão teria sido, conforme o relato do filme, perseguido e finalmente morto.

É desseângulo que o filme constitui um olhar novo sobreo Nordeste e o cangaço, temas muito explorados pelo cinema. 0 filme abandona a paisagem árida costumeira e entra nos meandros de um vale verdejante. Deixa de lado a viola e traz o som contemporâneo de Chico Science. Enfim, tem um ponto de vista novo sobre aquilo que conta.

Filmes com D ois corregos ou Baile perfumado, mesmo que não tenham a história como tema central, podem ter um sentido mais relevante do que muitos outros que julgam apreender todos os seus meandros.

Procuramos observar neste artigo formas de apropriação da H istória pelo cinema brasileiro na década de 1990. Ainda que aproximativo e não esgotando os títulos encenados no período, pudemos verificar como a H istória é entendida ainda, em grande medida, na forma tradicional do panteão e do exemplo. E o cinema diante dela é espelho, enão lugar de representação de nova e contínua compreensão. Lugar de reiteração, portanto. De esquecimento, como observava Foucault.

SCHVARZM AN, S. Staging H istory. H istória. São Paulo, v.22, n. 1, pp. 165 a 182, 2003.

A B S T RACT: History has been a constant subject on Brazilian films during the last decade of the $20^{\text {th }}$ century. Through the History, one tries to give credibility and prestige to the films, atracting investitors to financial then, according the new laws of culture incentive. $\mathrm{H}$ istory has became object of even more interest with the comemoration of five hundred years of arrived of Portuguese in Brazil, and the cinema has been encharged of production film about important moments and figures of the past times. This paper analyses how H istory was staging in these films and the results achieved.

KEY WORD s: Brazilian History, $90^{\text {th }}$ years, cinema and History. 


\section{NOTAS}

${ }^{1}$ Historiadora do Condephaat. Professora-visitante do Instituto de Artes da UNICAM P - 13083-970 - Campinas - SP.

${ }^{2}$ Nos anos 1920, foram realizadas três versões diferentes de 0 Guarani.

${ }^{3}$ Podemos fazer filmes históricos? A N oite, Rio de Janeiro, 1/5/1937.

${ }^{4}$ Para mais detalhes, ver o capítulo consagrado ao filme em SCHVARZM AN, S. Humberto M auro eas imagens do Brasil. (Tese de D outorado). Departamento de História, IFCH, Unicamp, 2000.

${ }^{5}$ Criada em 1948 pelo empresário italiano Franco Zampari, em associação com capitais de industriais paulistas.

${ }^{6}$ Termo criado por Salviano Cavalcanti de Paiva. Citado por BERNARDET, J. C. Trajetória do Cinema Brasileiro. Rio de Janeiro: Civilização Brasileira, 1968, p. 41.

' O sertão das memórias, de JoséA raújo; Baile Perfumado, de Lírio Caldas; Corisco e Dadá, de Rosemberg Cariri, todos de 1996. 0 tema já foi estudado por VIEIRA, M . D. S. Filme de cangaço: a representação do ciclo na década de 90 no cinema brasileiro. (Dissertação de M estrado). Instituto de Artes, U nicamp, 2001.

${ }^{8}$ A propósito, ver FREIRE, A. Canibalismo dos Fracos. Bauru: Edusc, 2002.

${ }^{9}$ Ver NA GIB, L. 0 Cinema da Retomada. São Paulo: Ed. 34, 2002.

${ }^{10}$ Basta lembrar, por exemplo, as publicações satíricas como SETÚ BAL, P. As sandices do Imperador. São Paulo: Saraiva, 1926.

${ }^{11}$ BERNARDET, J. C. Carlota Joaquina e o Cinema Brasileiro. Imagens. Campinas, Editora Unicamp, n. 5, p. 85, ago./dez. 1995, fala da “contestável teoria da história do filme".

${ }^{12}$ Idem.

${ }^{13}$ De acordo com Catálogo Cinema Brasileiro anos 90: 9 Q uestões. Rio de Janeiro: Centro Cultural Banco do Brasil, maio de 2001. Num universo de trinta e três filmes, oito foram de tema histórico.

${ }^{14}$ Conforme o documentário Os inconfidentes, de 1936, do Instituto Nacional de Cinema Educativo, dirigido por Humberto Mauro.

${ }^{15}$ Certamente uma das principais questões do cinema brasileiro, desde quando começou a ser pensado criticamente nos anos 1920, relaciona-se com a aparência ea qualidade do acabamento técnico. Depois de muitos anos que seriam de desajuste, nos quais predominou uma imagem ressentida junto ao público das elites e da classe média, a mudança deu-se nos anos 1990, marcados pelos ganhos em relação à qualidade técnica. É como se o cinema brasileiro, ao se aproximar de um padrão internacional de imagem neutra, finalmente se reconciliasse com o espectador. É 0 
caso do ordenado e bem composto conjunto habitacional do Nordeste que se pode ver em Central do Brasil.

${ }^{16}$ FOU CAULT, M . L'anti-retro. Cahiers du Cinéma, Paris, Éditions del'Étoile, n.25I252, p. 5, jui./aôut. 1974.

${ }^{17}$ FERRO, M. Introduction. In: DELAGE, C.; FLEURY-VILLATE. Révoltes, Révolutions, Cinema. Paris: Éditions Centre Pompidou, 1989, p. 5.

Artigo recebido em 04/2003. Aprovado em 05/2003. 